\title{
IMP3 Expression in Borderline Tumors of the Ovary
}

\author{
AHMED EL-BALAT $^{1}$, NICOLE SÄNGER $^{1}$, THOMAS KARN ${ }^{1}$, SVEN BECKER $^{1}$, \\ UWE HOLTRICH $^{1}$, ZELAL MUALLEM $^{2}$ and RUZA ARSENIC ${ }^{2}$ \\ ${ }^{1}$ Department of Obstetrics and Gynecology, Goethe University Frankfurt, Frankfurt, Germany; \\ ${ }^{2}$ Institute of Pathology, Charite University Hospital, Berlin, Germany
}

\begin{abstract}
Background/Aim: Borderline ovarian tumors (BOTs) have a less aggressive behavior than invasive epithelial ovarian tumors. Still some patients relapse or succumb to disease. Molecular markers that reliably predict prognosis are lacking. Insulin-like growth factor II mRNA-binding protein (IMP3) has been suggested as a prognostic marker in colorectal, hepatocellular, and ovarian clear-cell carcinomas. Materials and Methods: We analyzed the expression of IMP 3 by immunohistochemistry in a cohort of 140 BOT and its association with histopathological features. Results: We found no association of IMP3 expression with patients' age, FIGO stage, microinvasion, and presence of implants. In contrast, IMP3 expression correlated to mucinous subtype of BOTs ( $42.2 \%$ vs. $9.5 \%$ among other subtypes) $(p<0.001)$. IMP3 expression was found to be associated with the presence of in situ carcinoma in MBOT, but not in other subtypes $(p=0.021)$. Conclusion: Expression of IMP3 in BOT is associated with the mucinous subtype and may serve as an early indicator for the development of malignant features.
\end{abstract}

Borderline ovarian tumors (BOTs) are defined as epithelial tumors with a stratification of epithelial lining, but with no evidence of stromal invasion on pathologic examination. They have a less aggressive behavior than invasive epithelial ovarian tumors (1). They exist in various subtypes, including serous, mucinous (endocervical and intestinal type, of which intestinal type is more common), seromucinous, clear cell, endometrioid and Brenner (2). Molecular markers that could reliably differentiate between tumors with good or bad prognosis are lacking.

Correspondence to: Ahmed El-Balat, MD, Department of Obstetrics and Gynecology, Goethe University Frankfurt, Theodor-Stern-Kai 7, 60590 Frankfurt, Germany. Tel: +49 6963017438, Fax: +49 6963015522, e-mail: ahmed.el-balat@kgu.de

Key Words: Ovarian cancer, borderline tumors, histological subtypes, prognosis.
Insulin-like growth factor II mRNA-binding protein (IMP3) is involved in embryogenesis and it is rarely expressed in normal adult tissue and benign tumors. On the other hand, it has been reported to be expressed in a variety of malignant neoplasms. Consequently, IMP3 may act as a novel biomarker that can differentiate normal tissues from cancerous tissues $(3,4)$ and as already shown as a prognostic marker in colorectal, hepatocellular, and ovarian clear-cell carcinomas (5-7). Conflicting results have been reported for epithelial ovarian carcinoma (EOC), in which overexpression of IMP1, but not IMP3, was associated with advanced-stage, high-histological grade and poor survival (8). For borderline tumors of the ovary there are no data on IMP3 expression yet. Hence, the aim of this study was to evaluate the expression of IMP3 in borderline tumors of the ovary and to analyze potential relationships between clinical and pathological characteristics of BOTs and IMP3 expression.

\section{Materials and Methods}

Patients and samples. All analyses were performed according to the reporting recommendations for tumour marker prognostic studies (REMARK) (9). A cohort of 156 borderline tumors of the ovary (BOT) undergoing surgical resection was retrospectively assembled between January 1997 and September 2013 at the Goethe University Hospital in Frankfurt/Main, Germany. Formalin-fixed, paraffinembedded (FFPE) tissue samples were obtained from Senckenberg's Institute of Pathology, University Frankfurt (Frankfurt, Germany) and were re-evaluated by a second pathologist at the Institute of Pathology at the Charité Universitätsmedizin Berlin, Germany. For 140 of the samples with validated diagnosis sufficient archival material for immunohistochemical analysis was available. Pathological characteristics of this cohort are listed in Table I. The Local Research Ethics Committees approved studies of human tissue and samples were processed anonymously.

Histopathological evaluation and immunohistochemistry. Routine histopathology sections stained with haematoxylin-eosin were used for diagnosis and second reviewing by experienced pathologists. Diagnosis and classification was performed according to the current criteria of the World Health Organization (WHO) (10). After mounting on Superfrost Plus slides, paraffin sections $(2 \mu \mathrm{m})$ were dewaxed in xylene and rehydrated to water by a series of graduated 
ethanol. For antigen retrieval, sections were incubated for $20 \mathrm{~min}$ in a microwave oven $(800 \mathrm{~W})$ using EDTA buffer $(10 \mathrm{mmol} / \mathrm{l} ; \mathrm{pH}$ 8.0). Monoclonal anti-IMP3 antibody (Cat.\# M3626, clone 69.1, Lot.\# 10085605 Dako, Glostrup, Denmark) was used at a 1:100 dilution. Incubation with the antibody for 1 hour at room temperature was performed. For negative controls, the primary antibody was omitted. For secondary antibody incubation, the Dako REAL Detection System Alkaline Phosphatase/RED (Dako) was applied, following the instructions of the vendor. Sections were counterstained with hematoxylin. IMP3 were scored semiquantitatively based on the product of staining intensity (SI) and percentage of positively stained cells (PP) as a combined immunoreactive score (CIS): CIS=SI $\times$ PP. SI was assigned as 0 , negative; 1 , weak; 2 , moderate; or 3 , intense. PP was defined as 0 , none; $1,<25 \% ; 2,25-50 \% ; 3,51-75 \%$; or $4,>80 \%$ positive stained cells. All assessments were made blinded with respect to clinical patient data.

Statistical analysis. Chi-Square and Fisher's Exact Test were used to determine significance of categorical variables, Mann-Whitney $U$-Test for the analysis of continuous variables. All $\mathrm{p}$-values are two-sided and 0.05 was applied as significance level. Subjects with missing values were excluded from the analyses. All analyses were performed using SPSS Statistics Version 22 (IBM Corp., New York, NY, USA).

\section{Results}

Sample characteristics of the cohort. We retrospectively identified 156 cases of borderline tumor of the ovary (BOT) from pathology records. For 14 of the samples sufficient archival material was not available for staining, one sample was re-characterized as adenoma of the ovary and for one BOT only material from implants was available leaving a total of 140 BOT samples for analysis with anti-human IMP3 antibody. Median age of those 140 patients was 49.5 years (IQR 36.0-64.3). Additional sample characteristics are given in Table I. The majority of the samples were either of serous $(60.0 \%$, SBOT) or mucinous subtype $(32.1 \%$, MBOT). The high frequency of mucinous histology in BOT as compared to EOC has also been described by others (11). FIGO stage for most of the patients were either IA (30.0\%) or IC (37.9\%). Micropapillary pattern was observed for $22.9 \%$ (17.9\% partially) and implants were detected among $9.3 \%$ of the patients (Table I).

IMP3 expression in borderline tumors of the ovary. Next, IMP3 expression was analyzed by immuno-histochemical analysis of tissue samples from all 140 borderline tumors included in Table I. Examples of representative IMP3 staining results are shown in Figure 1. As previously reported, IMP3 is localized to the cytoplasm in BOT (12). Fibroblasts and endothelial cells were negative for IMP3 expression. No expression of IMP3 was observed in non-neoplastic epithelium. Intensity of staining and percentage of stained cells were scored separately and integrated as a combined
Table I. Sample characteristics.

\begin{tabular}{llrr}
\hline $\begin{array}{l}\text { Characteristic according } \\
\text { second pathology }\end{array}$ & $\mathrm{N}$ & $\%$ \\
\hline Subtype & Serous & 84 & $60.0 \%$ \\
& Mucinous & 45 & $32.1 \%$ \\
& Endometroid & 2 & $1.4 \%$ \\
FIGO stage & Mixed & 9 & $6.4 \%$ \\
& IA & 42 & $30.0 \%$ \\
& IB & 8 & $5.7 \%$ \\
& IC & 53 & $37.9 \%$ \\
& II & 7 & $5.0 \%$ \\
& III & 7 & $5.0 \%$ \\
Implants & IV & 1 & $0.7 \%$ \\
& N.A. & 22 & $15.7 \%$ \\
Micropapillary pattern & No & 127 & $90.7 \%$ \\
& Yes & 13 & $9.3 \%$ \\
Presence of $i n$ situ carcinoma* & No & 108 & $77.1 \%$ \\
& Partially & 25 & $17.9 \%$ \\
Microinvasion & No & 7 & $5.0 \%$ \\
& Yes & 121 & $90.7 \%$ \\
& No & 13 & $9.3 \%$ \\
& Yes & 137 & $97.9 \%$ \\
& & 3 & $2.1 \%$ \\
\hline
\end{tabular}

*According to WHO criteria: Cribriform glands measuring $5 \mathrm{~mm}$ in one dimension and nuclear atypia greater than that allowed in SBOT.

immuno-histochemical score (CIS, see Materials and Methods section). First, the distribution of the observed CIS was analyzed among the 140 BOT samples. Based on this distribution we stratified samples into three categories as following: no or weak IMP3 expression (CIS 0-9), medium IMP3 expression (CIS 10-19), or strong expression (CIS >19) (Figure 2). This stratification process resulted in 47 (33.6\%) negative or weak cases, $65(46.4 \%)$ medium and 28 strong (20.0\%) cases, respectively. We then compared this classification with sample characteristics as presented in Table II. We found no strong differences regarding patients' age, FIGO stage, microinvasion and the presence of implants between samples differing in IMP3 expression (Table II). In contrast, IMP3 expression was highly correlated to mucinous subtype of BOTs with $42.2 \%$ of samples with mucinous histology showing strong IMP3 expression compared to only $9.5 \%$ among other subtypes $(p<0.001$; Table II). Moreover, an inverse association between IMP3 and the presence of micropapillary pattern, was detected. All 32 samples with micropapillary pattern or partially micropapillary pattern showed weak or medium (CIS 0-19) staining for IMP3 and none showed strong IMP3 expression (CIS $>19)(p=0.002$; Table II). However, micropapillary pattern is only observed in the serous subtype (SBOT). Thus, we also repeated the analysis within the subgroup of SBOT to verify whether the observation was confounded by the association of IMP3 

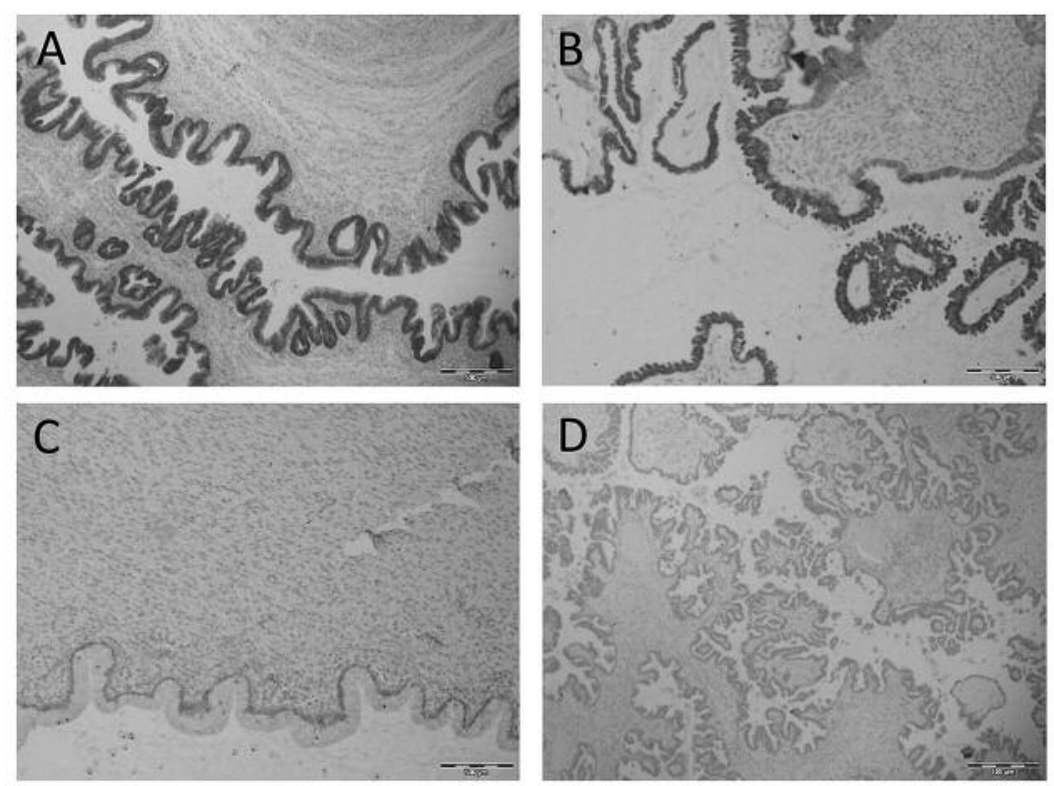

Figure 1. Immunohistochemichal detection of IMP3 expression in borderline tumors of the ovary. Mucinous borderline (A) and serous tumor (B) of the ovary showing strong cytoplasmic positivity for IMP3. Original magnification $\times 40 .(C)$ Mucinous borderline and (D) serous tumor of the ovary showing no positivity for IMP3. Original magnification $\times 40$.

expression with histological subtypes. As presented in Table III within serous subgroup we found no significant association of micropapillary pattern with IMP3 expression ( $p=0.107$; Table III). Assuming further confounding of IMP3 expression and sample characteristics through histological subtype all data were reanalyzed after stratification of the samples by subtype. No significant differences were observed for age, FIGO stage, microinvasion, and implants. However, as shown in Table IV, IMP3 expression was found to be associated with the presence of in situ carcinoma in mucinous BOT, but not in other subtypes ( $p=0.021$, Table IV).

\section{Discussion}

IMPs are members of a family of RNA-binding proteins comprising of IMP1, IMP2 and IMP3 which have been implicated in mRNA localization, nuclear export, turnover and translational control. The oncofetal protein IMP3 (IGF2 mRNA-Binding Protein 3) originally isolated from a pancreatic cancer tumor screen contains 2 functional RNA recognition motifs (RRM) in addition to $4 \mathrm{~K}$ Homology (KH) domains, which bind to target mRNA. Nielsen et al. (1999) demonstrated that IMP3 protein associates specifically with the 5-prime UTR of IGF2 mRNA, suggesting a role for IMP3 in the physiologic regulation of IGF2 protein production (13). In vitro studies have shown that IMP3 promotes tumor cell proliferation, adhesion, and invasion (14). IMPs are primarily expressed during early

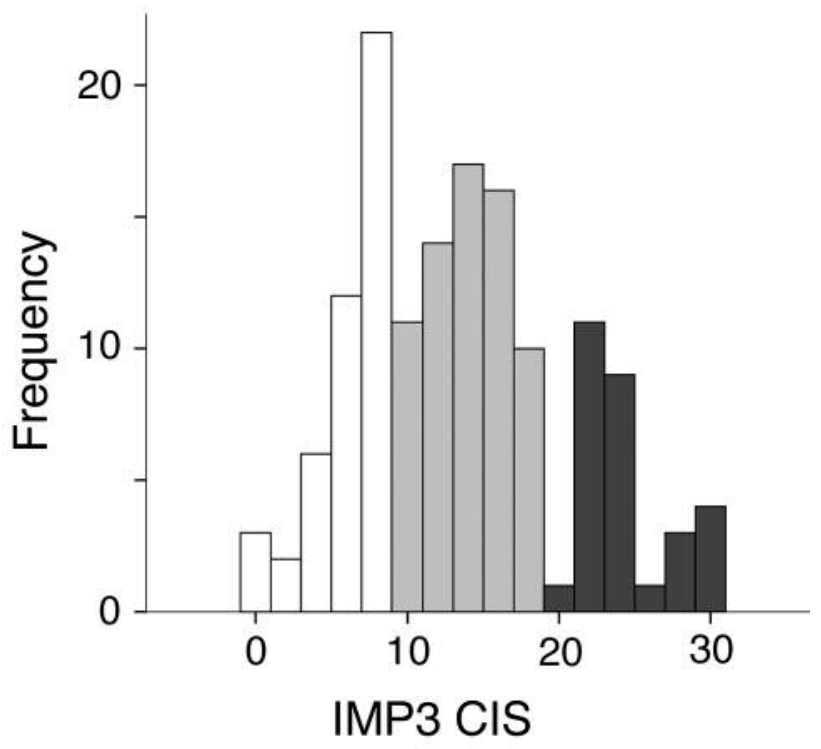

Figure 2. Distribution of IMP3 CIS scores in 140 borderline tumors of the ovary. Negative/weak IMP3 expression (CIS 0-9): blue; medium IMP3 expression (CIS 10-19): green; strong IMP3 expression (CIS >19): red.

embryogenesis (13), but IMP expression is also associated with a number of malignant neoplasms [reviewed in (15)]. The aim of this study was to evaluate the expression of IMP3 in borderline tumors of the ovary (BOT). We studied a cohort of 140 borderline tumors of the ovary, which to our 
Table II. IMP3 expression in borderline tumors of the ovary.

\begin{tabular}{|c|c|c|c|c|c|c|c|c|}
\hline \multicolumn{2}{|l|}{ Sample characteristic } & \multicolumn{2}{|c|}{$\begin{array}{l}\text { IMP3 negative/weak } \\
(\text { CIS }=0-9)\end{array}$} & \multicolumn{2}{|c|}{$\begin{array}{l}\text { IMP3 medium } \\
\text { (CIS 10-19) }\end{array}$} & \multicolumn{2}{|c|}{$\begin{array}{l}\text { IMP3 strong } \\
(\text { CIS }>19)\end{array}$} & \multirow[t]{2}{*}{$p$-Value } \\
\hline Frequency & & 47 & $33.6 \%$ & 65 & $46.4 \%$ & 28 & $20.0 \%$ & \\
\hline Median age & $(95 \% \mathrm{CI})$ & 49.2 & $(43.6-54.8)$ & 48.5 & $(44.3-55.6)$ & 45.9 & $(53.1-56.0)$ & $p=0.46$ \\
\hline \multirow[t]{5}{*}{ FIGO stage } & I & 29 & $23.8 \%$ & 52 & $57.1 \%$ & 23 & $19.0 \%$ & $p=0.25$ \\
\hline & II & 1 & $0.0 \%$ & 5 & $80.0 \%$ & 1 & $20.0 \%$ & \\
\hline & III & 4 & $66.7 \%$ & 2 & $33.3 \%$ & 0 & $0.0 \%$ & \\
\hline & IV & 1 & $100 \%$ & 0 & $0.0 \%$ & 0 & $0.0 \%$ & \\
\hline & N.A. & 12 & $57.1 \%$ & 6 & $28.6 \%$ & 3 & $14.3 \%$ & \\
\hline \multirow[t]{4}{*}{ Subtype } & Serous & 29 & $34.5 \%$ & 48 & $57.1 \%$ & 7 & $8.3 \%$ & $p<0.001$ \\
\hline & Mucinous & 14 & $31.1 \%$ & 12 & $26.7 \%$ & 19 & $42.2 \%$ & \\
\hline & Endometroid & 1 & $50.0 \%$ & 1 & $50.0 \%$ & 0 & $50.0 \%$ & \\
\hline & Mixed & 3 & $33.3 \%$ & 4 & $44.4 \%$ & 2 & $22.2 \%$ & \\
\hline \multirow[t]{2}{*}{ Presence of intraepithelial carcinoma } & No & 44 & $34.6 \%$ & 60 & $47.2 \%$ & 23 & $18.1 \%$ & $p=0.21$ \\
\hline & Yes & 3 & $23.0 \%$ & 5 & $38.5 \%$ & 5 & $38.5 \%$ & \\
\hline \multirow[t]{3}{*}{ Micropapillary pattern } & No & 37 & $34.3 \%$ & 43 & $39.8 \%$ & 28 & $25.9 \%$ & $p=0.002$ \\
\hline & Partially & 10 & $40.0 \%$ & 15 & $60.0 \%$ & 0 & $0.0 \%$ & \\
\hline & Yes & 0 & $0.0 \%$ & 7 & $100 \%$ & 0 & $0.0 \%$ & \\
\hline \multirow[t]{2}{*}{ Microinvasion } & No & 47 & $34.3 \%$ & 63 & $46.0 \%$ & 27 & $19.7 \%$ & $p=0.456$ \\
\hline & Yes & 0 & $0 \%$ & 2 & $66.7 \%$ & 1 & $3.6 \%$ & \\
\hline \multirow[t]{2}{*}{ Implants } & No & 41 & $32.0 \%$ & 60 & $46.9 \%$ & 27 & $21.1 \%$ & $p=0.366$ \\
\hline & Yes & 6 & $50.0 \%$ & 5 & $41.7 \%$ & 1 & $8.3 \%$ & \\
\hline
\end{tabular}

Table III. IMP3 expression and micropapillary pattern in SBOT.

\begin{tabular}{|c|c|c|c|c|c|c|}
\hline \multicolumn{2}{|l|}{ Sample characteristic } & \multicolumn{2}{|c|}{ IMP3 weak and medium } & \multicolumn{2}{|c|}{ IMP3 strong } & \multirow{2}{*}{$\begin{array}{c}p \text {-Value } \\
p=0.107\end{array}$} \\
\hline Micropapillary pattern & No & 46 & $86.8 \%$ & 7 & $13.2 \%$ & \\
\hline & Partially & 24 & $100.0 \%$ & 0 & $0.0 \%$ & \\
\hline & Yes & 7 & $100.0 \%$ & 0 & $0.0 \%$ & \\
\hline
\end{tabular}

knowledge represents the largest analysis of IMP3 in BOT up to date. The overall composition of our cohort with high prominence of SBOT and MBOT subtypes (64.5\% and $31.9 \%$ respectively) resembled those of large meta-analyses (11). We found a highly significant association of IMP3 positivity both with mucinous histology (MBOT) and with the presence of intraepithelial carcinoma $(p<0.001$ and $p=0.021$, respectively). Importantly, even within the MBOT subgroup the correlation of IMP3 with intraepithelial carcinoma is also significant $(p=0.044)$. In line with previous studies, strong IMP3 expression was rarely found expressed in SBOT $(8.3 \%)$, whereas a large portion of MBOT samples $(42.2 \%)$ displayed a CIS score $>19(12,16)$.

In invasive cancers, expression of IMP3 has been shown to correlate with a more aggressive tumor behavior and unfavorable prognosis. Köbel et al. assessed IMP3 expression in 475 ovarian carcinomas from a population-based cohort (6). Disease-specific survival was found to be significantly shorter in patients with IMP3 expressing clear cell carcinomas, whereas no significant difference in disease-specific survival was found for high-grade serous or endometrioid subtypes (6). Intriguingly, the highest rate of IMP3 expression in the ovarian carcinoma cohort was seen in the mucinous subtype $(86 \%$, $\mathrm{N}=30$ ), followed by clear cell carcinomas and high-grade serous carcinomas (6). This pattern of IMP3 staining among ovarian carcinoma subtypes is similar to that found in our BOT collection showing highest rates of IMP3 expression in MBOT $(42.2 \%)$ and only $8.3 \%$ in SBOT.

Recent studies suggested that Brenner and mucinous tumours originate from microscopic transitional cell nests at the tubal-mesothelial junction (17). In these tumours, their mucinous component becomes dominant when they grow. They compress and eventually obliterate the adjacent ovary giving the appearance that they arose in the ovary (17). Ovarian mucinous carcinogenesis has been postulated to be a sequential process starting with mucinous cystadenomas 
Table IV. IMP3 expression and presence of intraepithelial carcinoma in BOT subtypes.

\begin{tabular}{|c|c|c|c|c|c|c|c|c|}
\hline \multirow{2}{*}{$\begin{array}{l}\text { Sample } \\
\text { characteristic }\end{array}$} & \multirow{2}{*}{$\begin{array}{c}\begin{array}{c}\text { Intraepithelial } \\
\text { carcinoma }\end{array} \\
\text { No }\end{array}$} & \multicolumn{2}{|c|}{$\begin{array}{l}\text { IMP3 negative/ } \\
\text { weak }(\mathrm{CIS}=0-9)\end{array}$} & \multicolumn{2}{|c|}{$\begin{array}{l}\text { IMP3 medium } \\
\text { (CIS 10-19) }\end{array}$} & \multicolumn{2}{|c|}{$\begin{array}{l}\text { IMP3 strong } \\
(\text { CIS }>19)\end{array}$} & \multirow{2}{*}{$\begin{array}{c}p \text {-Value } \\
p=0.534\end{array}$} \\
\hline & & 28 & $35.4 \%$ & 44 & $55.7 \%$ & 7 & $8.9 \%$ & \\
\hline & Yes & 1 & $20.0 \%$ & 4 & $80.0 \%$ & 0 & $0.0 \%$ & \\
\hline \multirow[t]{2}{*}{ Mucinous } & No & 14 & $35.0 \%$ & 12 & $30.0 \%$ & 14 & $35.0 \%$ & $p=0.021$ \\
\hline & Yes & 0 & $0.0 \%$ & 0 & $0.0 \%$ & 5 & $100.0 \%$ & \\
\hline \multirow[t]{2}{*}{ Endometroid } & No & 0 & $0.0 \%$ & 0 & $0.0 \%$ & 0 & $0.0 \%$ & N.A. \\
\hline & Yes & 1 & $50.0 \%$ & 1 & $50.0 \%$ & 0 & $0.0 \%$ & \\
\hline \multirow[t]{2}{*}{ Mixed } & No & 2 & $28.6 \%$ & 4 & $57.1 \%$ & 1 & $14.3 \%$ & $p=0.386$ \\
\hline & Yes & 1 & $100.0 \%$ & 0 & $0.0 \%$ & 0 & $0.0 \%$ & \\
\hline
\end{tabular}

and progress through transitional stages of intraepithelial mucinous carcinoma and micro-invasive mucinous carcinoma, from which mucinous carcinoma develops (18). Borderline tumors with intraepithelial carcinoma and/or microinvasion provide evidence that these tumors form a morphologic spectrum with individual types representing steps in the sequence of mucinous carcinogenesis in the ovary (19). In our study we found that all MBOTs with intraepithelial carcinoma $(\mathrm{N}=5)$ are characterized by strong IMP3 expression in contrast to only $14 / 40$ (35\%) with no intraepithelial carcinoma $(p=0.021)$. This difference was not detected among SBOT $(p=0.53)$. Thus similar to reports on various human carcinomas the expression of IMP3 in MBOT may also be associated with a more aggressive phenotype of tumor-derived cells (20).

In summary, differential expression of IMP3 in BOT is associated with the mucinous subtype and may serve as an early indicator for the development of malignant features.

\section{Acknowledgements}

The Authors thank Katerina Brinkmann and Samira Adel for expert technical assistance. Furthermore, the authors thank Prof. Dr. M.L. Hansmann, Senckenberg's Institute of Pathology, University of Frankfurt, for providing formalin-fixed, paraffin-embedded tissue samples. This work was supported by grants from the Margarete Bonifer-Stiftung, Bad Soden, the H.W. \& J. Hector-Stiftung, Mannheim (grant number: M67), and the BANSS-Stiftung, Biedenkopf. No financial or personal conflict of interest by any of the Authors to declare.

\section{References}

1 Taylor HC: Malignant and semi-malignant tumors of the ovary. Surg Gynecol Obstet 48: 204-230, 1929.

2 Lalwani N, Shanbhogue AK, Vikram R, Nagar A, Jagirdar J and Prasad SR: Current update on borderline ovarian neoplasms. AJR Am J Roentgenol 194: 330-336, 2010.

3 Findeis-Hosey JJ and $\mathrm{Xu} \mathrm{H}$ : The use of insulin like-growth factor II messenger RNA binding protein-3 in diagnostic pathology. Hum Pathol 42: 303-314, 2011.
4 Yantiss RK, Woda BA, Fanger GR, Kalos M, Whalen GF, Tada H, Andersen DK, Rock KL and Dresser K: KOC (K homology domain containing protein overexpressed in cancer): a novel molecular marker that distinguishes between benign and malignant lesions of the pancreas. Am J Surg Pathol 29: 188-195, 2005.

5 Jeng YM, Chang CC, Hu FC, Chou HY, Kao HL, Wang TH and Hsu HC: RNA-binding protein insulin-like growth factor II mRNA-binding protein 3 expression promotes tumor invasion and predicts early recurrence and poor prognosis in hepatocellular carcinoma. Hepatology 48: 1118-1127, 2008.

6 Kobel M, Xu H, Bourne PA, Spaulding BO, Shih Ie M, Mao TL, Soslow RA, Ewanowich CA, Kalloger SE, Mehl E, Lee CH, Huntsman D and Gilks CB: IGF2BP3 (IMP3) expression is a marker of unfavorable prognosis in ovarian carcinoma of clear cell subtype. Mod Pathol 22: 469-475, 2009.

7 Lochhead P, Imamura Y, Morikawa T, Kuchiba A, Yamauchi M, Liao X, Qian ZR, Nishihara R, Wu K, Meyerhardt JA, Fuchs CS and Ogino $S$ : Insulin-like growth factor 2 messenger RNA binding protein 3 (IGF2BP3) is a marker of unfavourable prognosis in colorectal cancer. Eur J Cancer 48: 3405-3413, 2012.

$8 \mathrm{Gu} \mathrm{L}$, Shigemasa $\mathrm{K}$ and Ohama K: Increased expression of IGF II mRNA-binding protein $1 \mathrm{mRNA}$ is associated with an advanced clinical stage and poor prognosis in patients with ovarian cancer. Int J Oncol 24: 671-678, 2004.

9 McShane LM, Altman DG, Sauerbrei W, Taube SE, Gion M, Clark GM and Statistics Subcommittee of the NCIEWGoCD: Reporting recommendations for tumor marker prognostic studies (REMARK). J Natl Cancer Inst 97: 1180-1184, 2005.

10 Kurman RJ: WHO Classification of Tumours of Female Reproductive Organs. Fourth Edition 4: 307, 2014.

11 du Bois A, Ewald-Riegler N, de Gregorio N, Reuss A, Mahner S, Fotopoulou C, Kommoss F, Schmalfeldt B, Hilpert F, Fehm T, Burges A, Meier W, Hillemanns P, Hanker L, Hasenburg A, Strauss HG, Hellriegel M, Wimberger P, Keyver-Paik MD, Baumann K, Canzler U, Wollschlaeger K, Forner D, Pfisterer J, Schroder W, Munstedt K, Richter B, Kommoss S, Hauptmann S and Arbeitsgmeinschaft Gynakologische Onkologie Study G: Borderline tumours of the ovary: A cohort study of the Arbeitsgmeinschaft Gynakologische Onkologie (AGO) Study Group. Eur J Cancer 49: 1905-1914, 2013.

12 Chiste M, Alexis $\mathrm{J}$ and Recine M: IMP3 expression in serous tumors of the ovary. Appl Immunohistochem Mol Morphol 22: 658-662, 2014. 
13 Nielsen J, Christiansen J, Lykke-Andersen J, Johnsen AH, Wewer UM and Nielsen FC: A family of insulin-like growth factor II mRNA-binding proteins represses translation in late development. Mol Cell Biol 19: 1262-1270, 1999.

14 Vikesaa J, Hansen TV, Jonson L, Borup R, Wewer UM, Christiansen J and Nielsen FC: RNA-binding IMPs promote cell adhesion and invadopodia formation. EMBO J 25: 1456-1468, 2006.

15 Jordan SJ, Green AC, Whiteman DC, Webb PM and Australian Ovarian Cancer Study G: Risk factors for benign, borderline and invasive mucinous ovarian tumors: epidemiological evidence of a neoplastic continuum? Gynecol Oncol 107: 223-230, 2007.

16 Noske A, Faggad A, Wirtz R, Darb-Esfahani S, Sehouli J, Sinn B, Nielsen FC, Weichert W, Buckendahl AC, Roske A, Muller B, Dietel M and Denkert C: IMP3 expression in human ovarian cancer is associated with improved survival. Int $\mathrm{J}$ Gynecol Pathol 28: 203-210, 2009.

17 Seidman JD and Khedmati F: Exploring the histogenesis of ovarian mucinous and transitional cell (Brenner) neoplasms and their relationship with Walthard cell nests: a study of 120 tumors. Arch Pathol Lab Med 132: 1753-1760, 2008.
18 Nomura K, Aizawa S and Hano H: Ovarian mucinous borderline tumors of intestinal type without intraepithelial carcinoma: are they still tumors of low malignant potential? Pathol Int 54: 420424, 2004.

19 Fischerova D, Zikan M, Dundr P and Cibula D: Diagnosis, treatment, and follow-up of borderline ovarian tumors. Oncologist 17: 1515-1533, 2012.

20 Lederer M, Bley N, Schleifer C and Huttelmaier S: The role of the oncofetal IGF2 mRNA-binding protein 3 (IGF2BP3) in cancer. Semin Cancer Biol 29: 3-12, 2014.

Received November 25, 2016

Revised December 23, 2016

Accepted December 28, 2016 